\title{
Ruokinnan vaikutus sian lihaksiin ja lihan laatuun
}

\author{
Marita Ruusunen $^{1)}$, Kirsi Partanen ${ }^{2)}$, Reeta Pösö ${ }^{3)}$ ja Eero Puolanne ${ }^{1)}$ \\ ${ }^{1)}$ HY/elintarviketeknologian laitos, Viikki EE, PL 66, 00014 Helsingin yliopisto, \\ marita.ruusunen@helsinki.fi,eero.puolanne@helsinki.fi \\ ${ }^{2)}$ MTT, Sikatalous, Tervamäentie 179,05840 Hyvinkää, kirsi.partanen@mtt.fi \\ ${ }^{3)}$ HY/peruseläinlääketieteen laitos, Viikki EE, PL 66,00014 Helsingin yliopisto, reeta.poso@helsinki.fi
}

\section{Tiivistelmä}

Tutkimuksessa selvitettiin, miten rehun lysiinipitoisuus vaikuttaa sian lihasolujen ominaisuuksiin, lihan pH:n laskuun teurastuksen jälkeen ja lihan laatuun. Tutkimuksessa oli $40 \mathrm{kpl} 165$ vuorokauden ikäistä sikaa 20 pahnueesta. Rodultaan siat olivat maatiaisia, yorkshireja ja niiden risteytyksiä. Sioista puolet oli imisiä ja puolet leikkoja. Siat ruokittiin rehulla, jossa oli $6 \mathrm{~g}$ (matala-lysiiniryhmä) tai 9,5 g sulavaa lysiiniä (korkea-lysiiniryhmä) rehuyksikössä (1 ry = 9,3 MJ NE). Siat saivat rehua runsasniukkanormin mukaan 1,4-3,2 ry/pv. Enemmän lysiiniä saaneet siat saivat myös enemmän proteiineja. Kokeen lopussa korkea-lysiiniryhmän siat saivat noin $124 \mathrm{~g}$ enemmän proteiinia päivässä kuin matalalysiiniryhmän siat. Sikojen elopaino oli teurastettaessa keskimäärin $105 \mathrm{~kg}(86-118,5 \mathrm{~kg})$.

Tutkittavat lihakset olivat $M$. longissimus dorsi (ulkofilee), M. semimembranosus (sisäpaisti) ja M. gluteus superficialis (paahtopaisti). Lihaksista määritettiin lihassolutyyppikoostumus: punaisten, välimuotoa olevien ja valkoisten lihassolujen prosenttiosuudet laskettuna pinta-alaosuuksien perusteella. Lihassolujen koko määritettiin mittaamalla lihassolujen poikkipinta-alat. Kapillaaritiheys määritettiin laskemalla kapillaarien (hiusverisuonien) määrä neliömillimetriä kohti. Määritykset tehtiin kuvankäsittelyohjelman avulla. Lisäksi määritettiin lihasten glykolyyttinen potentiaali glykogeeni- ja laktaattipitoisuuksien perusteella. pH:n laskunopeus ruhossa määritettiin mittaamalla ulkofileen $\mathrm{pH}$-arvo 45 minuuttia teurastuksen jälkeen. Lihasten $\mathrm{pH}$-arvo, valuma ja väri [L* (vaaleus), $\mathrm{a}^{*}$ (punaisuus) ja $\mathrm{b}^{*}$ (keltaisuus)] mitattiin kaikista lihaksista 24 tuntia teurastuksen jälkeen.

Lihassolutyyppikoostumus oli samanlainen molempien ruokintaryhmien kaikissa tutkituissa lihaksissa. Ruokinta vaikutti lihassolujen kokoon. Lihassolut olivat keskimäärin pienempiä matalalysiiniryhmän sioissa kuin korkea-lysiiniryhmän sioissa. Matala-lysiiniryhmän sikojen lihaksissa oli suurempi kapillaaritiheys $\left(\mathrm{kpl} / \mathrm{mm}^{2}\right)(\mathrm{P}<0,05)$. Tämä johtui lihassolujen pienemmästä koosta, koska kapillaarit sijaitsevat lihassolujen reunoilla. Syynä pienempiin lihassolun poikkipinta-aloihin matalalysiiniryhmän sioissa oli sekä pienempi elopaino että suurempi ruhon rasvapitoisuus.

Glykolyyttinen potentiaali kuvaa lihaksen glykogeenipitoisuutta teurastushetkellä ottaen huomioon myös glykogeenimäärän, joka hajoaa laktaatiksi teurastuksen ja näytteenoton välillä. Glykolyyttisen potentiaalin määrittämiseksi määritettiin erikseen glykogeeni- ja laktaattipitoisuus. Matala-lysiiniryhmässä longissimus dorsi ja semimembranosus -lihasten glykolyyttinen potentiaali oli korkeampi kuin korkea-lysiiniryhmässä $(\mathrm{P}<0,05)$. Vähemmän lysiiniä saaneiden rasvaisempien ruhojen lihaksissa oli enemmän glykogeenia, minkä seurauksena ruhon $\mathrm{pH}$ laski nopeammin teurastuksen jälkeen kuin paljon lysiiniä saaneissa sioissa. Lihan loppu-pH-arvoon, valumaan ja lihan väriin ruokinnalla ei ollut vaikutusta.

Johtopäätöksenä voidaan todeta, että vähän lysiiniä saaneiden sikojen vaaleissa lihaksissa lihassolut olivat pienempiä, lihasten glykolyyttinen potentiaali oli korkeampi ja pH-arvo laski nopeammin teurastuksen jälkeen kuin enemmän lysiiniä saaneilla. Ilmeisesti syy eroihin tutkituissa ominaisuuksissa oli myös ero proteiinipitoisuudessa. Hyvän lihan laadun kannalta on tärkeää, että siat ruokitaan riittävän hyvin. Lihasten glykogeenipitoisuuteen teurastushetkellä on kiinnitettävä huomiota, ettei se nouse liian suureksi, etenkin jos käytetään glykogeenia säästäviä teurastustapoja.

Asiasanat: sika, lysiini, proteiini, lihas, lihan laatu 


\section{Johdanto}

Ruhossa on sekä tummia että vaaleita lihaksia. Vaaleat lihakset koostuvat pääosin valkoisista lihassoluista ja tummat punaisista ja välimuotoa olevista. Teurastuksen jälkeiset muutokset tapahtuvat näissä lihaksissa eri tavalla. Vaaleat lihakset sisältävät paljon glykogeenia. Glykogeenin pilkkoutuminen lihaksessa laktaatiksi teurastuksen jälkeen aiheuttaa lihan $\mathrm{pH}: n$ laskun. Vaaleissa lihaksissa pH-arvo laskee nopeammin teurastuksen jälkeen ja myös loppu-pH-arvo on alempi kuin tummissa lihaksissa. Vaaleiden lihasten loppu-pH-arvo on noin 5,5 ja tummien lihasten noin 5,9.

Lihan laadun mittana käytetään $\mathrm{pH}$-arvoa mitattuna ulkofileestä 45 minuuttia teurastuksen jälkeen. Jos pH-arvo on tällöin alle 5,8, lihasta tulee PSE-lihaa (vaalea, pehmeä ja vetinen liha) (Honikel ja Kim, 1985). PSE-lihan syynä on sian liiallinen stressaantuminen välittömästi ennen teurastusta. PSE-lihaisuutta esiintyy yleensä vain vaaleissa lihaksissa. Tervalihaa (DFD-liha: tumma, kiinteä ja kuiva liha) muodostuu puolestaan pitkäaikaisen stressin seurauksena. Tervalihaksi kutsutaan sianlihaa, jonka pH-arvo mitattuna 24 tuntia teurastuksesta on yli 6,1 (Barton-Gade, 1981).

Glykogeenin määrä lihaksessa teurastushetkellä määrää sen, kuinka alas lihaksen pH-arvo laskee, mutta vain jos lihaksen glykogeenipitoisuus on $53 \mathrm{mmol} / \mathrm{kg}$ tai alempi (Henckel ym. 2002). Tällöin loppu-pH-arvo jää normaalia korkeammaksi. Korkeammilla glykogeenipitoisuuksilla ei yleensä ole yhteyttä lihan loppu-pH-arvoon. Glykolyyttinen potentiaali kuvaa lihaksen glykogeenipitoisuutta teurastushetkellä ottaen huomioon myös glykogeenimäärän, joka hajoaa laktaatiksi teurastuksen ja näytteenoton välillä. Glykolyyttisen potentiaalin määrittämiseksi määritettiin erikseen lihaksen glykogeeni- ja laktaattipitoisuudet. Lihasten glykogeenipitoisuuteen teurastushetkellä vaikuttavat mm. ruokinta, teuraskuljetus, navettaolosuhteet ja tainnutustapa. Tämän vuoksi glykogeenipitoisuuden hallinta erilaisissa teurastusolosuhteissa on vaikeaa.

Tutkimuksessa selvitettiin, miten rehun lysiinipitoisuus vaikuttaa lihasolujen ominaisuuksiin, pH:n laskuun teurastuksen jälkeen sekä lihan laatuun. Enemmän lysiiniä saaneet saivat myös enemmän proteiineja. Kokeen lopussa korkea-lysiiniryhmän siat saivat noin $124 \mathrm{~g}$ enemmän proteiinia päivässä kuin matala-lysiiniryhmän siat.

Tulokset ovat osa laajemmasta tutkimusprojektista, jossa tutkittiin sianruhon ominaisuuksia, elinten kokoa, vaaleiden ja tummien lihasten oksidatiivisia ja glykolyyttisiä ominaisuuksia, veren kemiaa ja näiden ominaisuuksien sekä mitattujen arvojen yhteyttä lihan laatuun sioissa, jotka kasvoivat eri nopeudella (Puolanne ym. 2003). Erot kasvunopeudessa saatiin aikaan muuttamalla rehun lysiini/proteiinipitoisuutta. Hankkeessa olivat mukana Helsingin yliopisto elintarviketeknologian ja peruseläinlääketieteen laitokset ja MTT:n sikatalouden tutkimusasema.

\section{Aineisto ja menetelmät}

\section{Kasvatus ja teurastus}

Kaikkiaan tutkittiin 40 sikaa 20 pahnueesta. Rodultaan siat olivat maatiaisia, yorkshireja ja niiden risteytyksiä. Sioista puolet oli imisiä ja puolet leikkoja. Siat ruokittiin rehulla, jossa oli joko $6 \mathrm{~g}$ (matala-lysiiniryhmä) tai 9,5 g sulavaa lysiiniä (korkea-lysiiniryhmä) rehuyksikössä (1 ry=9,3 MJ $\mathrm{NE}$ ). Enemmän lysiiniä saaneet siat söivät myös enemmän proteiinia. Ruokintanormi oli runsasniukka ja siat saivat rehua (1,4-3,2 ry/pv). Siat teurastettiin $165 \pm 2$ vrk:n ikäisinä HY:n elintarviketeknologian laitoksen koetehtaassa. Sikojen elopaino vaihteli teurastettaessa 86 - 118,5 kg:n välillä ollen keskimäärin $105 \mathrm{~kg}$.

\section{Lihastutkimukset}

\section{Lihassolutyyppijakauma}

Lihasnäytteet otettiin noin 30 minuuttia teurastuksen jälkeen longissimus dorsi, semimembranosus ja gluteus superficialis -lihaksista (ulkofilee, sisäpaisti ja paahtopaisti). Lihasnäytteet jäädytettiin nestemäisessä typessä ja säilytettiin -80 asteessa. Lihaksista määritettiin lihassolutyyppikoostumus myosiini-ATPaasimenetelmällä (Brooke ja Kaiser, 1970). Menetelmällä erotetaan punaiset, välimuotoa olevat ja valkoiset lihassolut toisistaan. Lihassolujen prosenttiosuudet laskettiin pintaalaosuuksien perusteella. Lisäksi mitattiin lihassolujen koko mittaamalla lihassolujen poikkipinta-alat. Lihassolun keskimääräinen pinta-ala laskettiin jakamalla analysoitava lihasala lihassolujen lukumäärällä. Kapillaarit määritettiin Andersenin (1975) menetelmällä. Kapillaaritiheys (kpl 
kapillaareja $/ \mathrm{mm}^{2}$ ) määritettiin laskemalla kapillaarien (hiusverisuonien) määrä neliömillimetriltä. Laskenta tehtiin kuvankäsittelylaitteella käyttämällä KS300-kuvankäsittelyohjelmaa (KS 300 Imagin System Release 3.0, Carl Zeiss Vision Imagin Systems).

\section{Glykolyyttinen potentiaali}

Lihaksista määritettiin glykolyyttinen potentiaali, joka kuvaa lihaksen glykogeenipitoisuutta teurastushetkellä ottaen huomioon myös teurastuksen ja näytteenoton välillä laktaatiksi hajonneen glykogeenin. Glykolyyttisen potentiaalin määrittämiseksi määritettiin erikseen lihan glykogeeni- ja laktaattipitoisuus. Glykogeenipitoisuus määritettiin glukoosina Roche/Hitachin määrityskitillä no. 1447521 ja laktaattipitoisuus Boehringer-Mannheimin määrityskitillä no. 139084 (Immonen 2000). Glykolyyttinen potentiaali (GP) laskettiin Monin'in ja Sellier'in (1985) mukaan: Glykolyyttinen potentiaali mmol laktaattia/kg lihaa $=[2 *$ (glykogeeni + glukoosi + glukoosi-6-fosfaatti $)+$ laktaatti $]$. Glykogeeni, glukoosi ja glukoosi-6-fosfaatti määritettiin samanaikaisesti.

\section{Lihan laatututkimukset}

Lihan pH mitattiin Xerolyt-elektrodilla (Mettler Toledo Inlab 427) käyttäen Portamess 752 Calimatic -pH-mittaria. 45 minuuttia tainnutuksen jälkeen $\mathrm{pH}$ mitattiin Na-I-asetaattiliuoksesta $\left(\mathrm{pH}_{45}\right)$ homogenoimalla noin yhden gramman näyte Na-I-asetaattiliuokseen (1:10). Seuraavana päivänä jäähdytyksen jälkeen $\mathrm{pH}$-arvo $\left(\mathrm{pH}_{24}\right)$ mitattiin suoraan lihaksesta.

Väri [L*(vaaleus), $a^{*}$ (punaisuus), $b^{*}$ (keltaisuus)] mitattiin CIE järjestelmään perustuvalla Minolta- värinmittauslaitteella. Kalibrointi tehtiin valkoiseen levyyn ja valonlähde oli D65. Lihaspalaa pidettiin 15 min huoneen lämpötilassa valossa, minkä jälkeen väri mitattiin kolmesta eri kohdasta. Väriarvot ovat näiden kolmen mittauksen keskiarvoja.

Valuman määrittämiseksi lihaksista leikattiin suunnilleen samankokoiset kappaleet (à 60-80 g), kolme rinnakkaista näytettä per lihas. Näyte laitettiin Minigrip-pussiin ja liha ommeltiin kiinni pussin yläreunaan siten, että neste pääsi valumaan pussin pohjalle. Lihapaloja pidettiin 4 vrk $4 \mathrm{C}$-asteessa, minkä jälkeen irronneen nesteen määrä punnittiin. Valuma ilmoitettiin prosentteina.

\section{Tilastollinen analyysit}

Erot ruokintaryhmien välillä testattiin varianssianalyysillä (SAS 1999).

\section{Tulokset ja tulosten tarkastelu}

\section{Lihassolujen ominaisuudet}

Kaikki tutkitut lihakset olivat vaaleita, joissa valkoisten lihassolujen osuus pinta-alasta oli $90 \%$ (Taulukko 1). Lihassolutyyppikoostumus oli samanlainen molempien ruokintaryhmien kaikissa tutkituissa lihaksissa $(p>0,05)$. Matala-lysiiniryhmän sioissa lihassolut olivat keskimäärin pienempiä kuin korkea-lysiiniryhmän sioissa. Matala-lysiiniryhmän sikojen lihaksissa oli suurempi kapillaaritiheys $\left(\mathrm{kpl}\right.$ kapillaareja $\left./ \mathrm{mm}^{2}\right)(\mathrm{P}<0,05)$ johtuen pienemmästä lihassolujen koosta, koska kapillaarit sijaitsevat lihassolujen reunoilla. Syy pienempiin lihassolun poikkipinta-aloihin matalalysiiniryhmän sioissa oli puolestaan sekä pienempi elopaino että suurempi ruhon rasvapitoisuus.

\section{Glykolyyttinen potentiaali}

Glykogeenipitoisuus kuvaa eläimen hyvinvoinnin tilaa sellaisissa tilanteissa, joissa lihasten glykogeenivarastot ovat hyvin pienet teurastushetkellä. Vaaleissa lihaksissa on normaalisti paljon glykogeenia, joka pilkkoutuu laktaatiksi teurastuksen jälkeen ja aiheuttaa $\mathrm{pH}: n$ laskun. Vaaleissa lihaksissa on myös paljon glykogeenia hajottavia entsyymejä, mikä myös nopeuttaa glykogeenin hajoamista. Lihaksen alhainen glykogeenipitoisuus on osoitus siitä, että sika on altistunut pitkäaikaiselle stressille ennen teurastusta. Jos glykogeenipitoisuus teurastushetkellä on $53 \mathrm{mmol} / \mathrm{kg}$ tai alempi (Henckel ym. 2002), loppu-pH-arvo jää normaalia korkeammaksi. Paasto ja sikojen pitäminen teurastamon navetassa yli yön pienentävät myös jonkin verran glykogeenivarastoja. Glykolyyttinen potentiaali kuvaa lihaksen glykogeenipitoisuutta teurastushetkellä ottaen huomioon myös glykogeenimäärän, joka hajoaa laktaatiksi teurastuksen ja näytteenoton välillä. Glykolyyttisen potentiaalin määrittämiseksi on määritettävä erikseen glykogeeni- ja laktaattipitoisuus. Tässä tutkimuksessa matala-lysiiniryhmässä sian longissimus dorsi ja semimembranosus -lihasten 
glykolyyttinen potentiaali oli korkeampi kuin korkea-lysiiniryhmässä $(\mathrm{P}<0,05)$ (Taulukko 1). Lihasten glykogeenipitoisuuteen teurastushetkellä vaikuttavat mm. ruokinta, teuraskuljetus, navettaolosuhteet ja tainnutustapa. Tämän vuoksi glykogeenipitoisuuden hallinta erilaisissa teurastusolosuhteissa on vaikeaa.

Taulukko 1. Lihassolutyyppien prosenttiosuudet laskettuna pinta-ala osuuksien (\%) perusteella, lihassolujen poikkipinta-alat $(\mathrm{CSA})$ ja kapillaaritiheys $\left(\mathrm{kpl} / \mathrm{mm}^{2}\right)$ ruokintaryhmittäin $(\mathrm{N}=20$ per ruokintaryhmä, keskiarvot ja standardipoikkeamat (s.d.)).

$\begin{array}{llclc}\begin{array}{c}\text { Matala-lysiini } \\ \text { Ka. }\end{array} & \text { s.d } & \text { Korkea-lysiini } & \text { Ka. } & \text { P }\end{array}$

\begin{tabular}{|c|c|c|c|c|c|}
\hline \multicolumn{6}{|l|}{ M. longissimus dorsi } \\
\hline 1)\% punaisia & 6,3 & 2,1 & 6,7 & 1,9 & \\
\hline 1)\% välimuotoa olevia & 2,9 & 1,5 & 3,6 & 2,2 & \\
\hline 1)\% valkoisia & 90,9 & 2,4 & 89,8 & 2,1 & \\
\hline${ }^{2)} \mathrm{CSA}_{\text {pun }}, 1000 \mu \mathrm{m}^{2}$ & 2,71 & 0,45 & 3,19 & 0,53 & $*$ \\
\hline${ }^{3)} \mathrm{CSA}_{\mathrm{vm}}, 1000 \mu \mathrm{m}^{2}$ & 2,38 & 0,68 & 3,12 & 0,79 & $*$ \\
\hline 4) $\mathrm{CSA}_{\text {valk }}, 1000 \mu \mathrm{m}^{2}$ & 5,18 & 0,95 & 6,40 & 1,06 & $*$ \\
\hline${ }^{5)} \mathrm{CSA}_{\text {lihassolu }}, 1000 \mu \mathrm{m}^{2}$ & 4,72 & 0,79 & 5,77 & 0,88 & $*$ \\
\hline Kapillaarit (kpl/mm²) & 175 & 28 & 149 & 30 & $*$ \\
\hline \multicolumn{6}{|l|}{ M. semimembranosus } \\
\hline 1) $\%$ punaisia & 6,7 & 1,7 & 6,5 & 1,6 & \\
\hline 1)\% välimuotoa olevia & 3,6 & 1,4 & 3,7 & 1,8 & \\
\hline 1) $\%$ valkoisia & 89,8 & 2,1 & 89,9 & 2,2 & \\
\hline${ }^{2)} \mathrm{CSA}_{\text {pun }}, 1000 \mu \mathrm{m}^{2}$ & 2,97 & 0,59 & 3,13 & 0,53 & \\
\hline${ }^{3)} \mathrm{CSA}_{\mathrm{vm}}, 1000 \mu \mathrm{m}^{2}$ & 3,39 & 0,82 & 3,57 & 0,64 & \\
\hline 4) $\mathrm{CSA}_{\text {valk }}, 1000 \mu \mathrm{m}^{2}$ & 5,99 & 1,00 & 6,43 & 0,79 & \\
\hline${ }^{5)} \mathrm{CSA}_{\text {lihassolu }}, 1000 \mu \mathrm{m}^{2}$ & 5,44 & 0,84 & 5,85 & 0,72 & \\
\hline Kapillaarit $\left(\mathrm{kpl} / \mathrm{mm}^{2}\right)$ & 228 & 24 & 204 & 43 & $*$ \\
\hline \multicolumn{6}{|l|}{ M. gluteus superficialis } \\
\hline 1)\% punaisia & 6,8 & 1,4 & 6,9 & 1,2 & \\
\hline 1)\% välimuotoa olevia & 4,1 & 1,7 & 3,8 & 1,7 & \\
\hline 1)\% valkoisia & 89,2 & 2,2 & 89,3 & 1,9 & \\
\hline${ }^{2)} \mathrm{CSA}_{\mathrm{pun}}, 1000 \mu \mathrm{m}^{2}$ & 2,76 & 0,50 & 3,00 & 0,73 & \\
\hline${ }^{3)} \mathrm{CSA}_{\mathrm{vm}}, 1000 \mu \mathrm{m}^{2}$ & 3,11 & 0,70 & 3,73 & 1,2 & \\
\hline${ }^{4)} \mathrm{CSA}_{\text {valk }}, 1000 \mu \mathrm{m}^{2}$ & 5,42 & 0,69 & 6,47 & 1,33 & $*$ \\
\hline${ }^{5)} \mathrm{CSA}_{\text {lihassolu }}, 1000 \mu \mathrm{m}^{2}$ & 4,94 & 0,58 & 5,73 & 1,10 & $*$ \\
\hline Kapillaarit (kpl/mm²) & 204 & 31 & 178 & 33 & $*$ \\
\hline \multicolumn{6}{|l|}{$\begin{array}{l}\text { Glykolyyttinen potentiaali } \\
\text { (mmol laktaattia } / \mathrm{kg} \text { ) }\end{array}$} \\
\hline M. longissimus dorsi & 212,1 & 39,1 & 182,0 & 39,5 & $*$ \\
\hline M. semimembranosus & 182,1 & 35,7 & 160,4 & 27,6 & $*$ \\
\hline M. gluteus superficialis & 202,8 & 46,8 & 183,8 & 53,8 & \\
\hline
\end{tabular}

\section{Lihan laatu}

Eräs lihan laadun mitta on $\mathrm{pH}$-arvo mitattuna longissimus dorsi -lihaksesta 45 minuuttia teurastuksen jälkeen. Matala-lysiini/proteiiniryhmän longissimus dorsi -lihaksen $\mathrm{pH}_{45}$-arvo oli alempi $(\mathrm{P}<0,05)$ kuin korkea-lysiini/proteiiniryhmässä (Taulukko 2). Tutkimuksessa oli viisi PSE:ksi luokiteltavaa sikaa, neljä matala-lysiiniryhmässä ja yksi korkea-lysiiniryhmässä. Eräs syy alempaan $\mathrm{pH}_{45}$ arvoon oli korkeampi glykolyyttinen potentiaali matala-lysiiniryhmä sikojen longissimus dorsi -lihaksessa 
$(\mathrm{P}<0,05)$. (Taulukko 1). Alempi pH-arvo 45 minuuttia teurastuksen jälkeen aiheutti myös vähemmän lysiiniä/proteiinia saaneiden sikojen lihaksissa suuremman valuman, vaikka ero ei ollutkaan merkitsevä $(\mathrm{P}>0,05)$. Lihan loppu-pH-arvoon, lihan vaaleuteen $\left(\mathrm{L}^{*}\right.$-arvo) ja keltaisuuteen ( $\mathrm{b}^{*}$-arvo) ruokinnalla ei ollut vaikutusta, mutta matala-lysiiniryhmän longissimus dorsi -lihas oli punaisempi (a*-arvo) kuin korkea-lysiiniryhmän $(\mathrm{P}<0,05)$.

Lihan laadun kannalta on tärkeää ottaa huomioon kaikki ne tekijät, jotka vaikuttavat pH:n laskunopeuteen ja laskun määrään teurastuksen jälkeen. Yleensä pH-arvo mitattuna 45 minuuttia teurastuksen jälkeen kertoo valuman stressiherkissä sioissa. Normaaleissa sioissa parempi indikaattori valumalle on mitata lihaksen lämpötila yksi minuutti tainnutuksen jälkeen ja/tai lihaksen $\mathrm{pH}$-arvo kaksi tuntia tainnutuksen jälkeen (Schäfer ym. 2002). Lihaksen loppu-pH-arvo ei yleensä kerro valuman määrää etenkään silloin, kun hajonta loppu-pH-arvoissa on hyvin pieni. Tässä tutkimuksessa lihasten loppu-pH-arvot vaihtelivat hyvin vähän (Taulukko 2), minkä vuoksi loppu-pH-arvon ja valuman välillä ei todettu yhteyttä, mutta alhainen $\mathrm{pH}$-arvo 45 minuuttia teurastuksen jälkeen lisäsi valumaa.

Taulukko 2. Lihasian lihan laatuparametrit ruokintaryhmittäin ( $N=20$ per ruokintaryhmä, keskiarvot ja standardipoikkeamat (s.d.)).

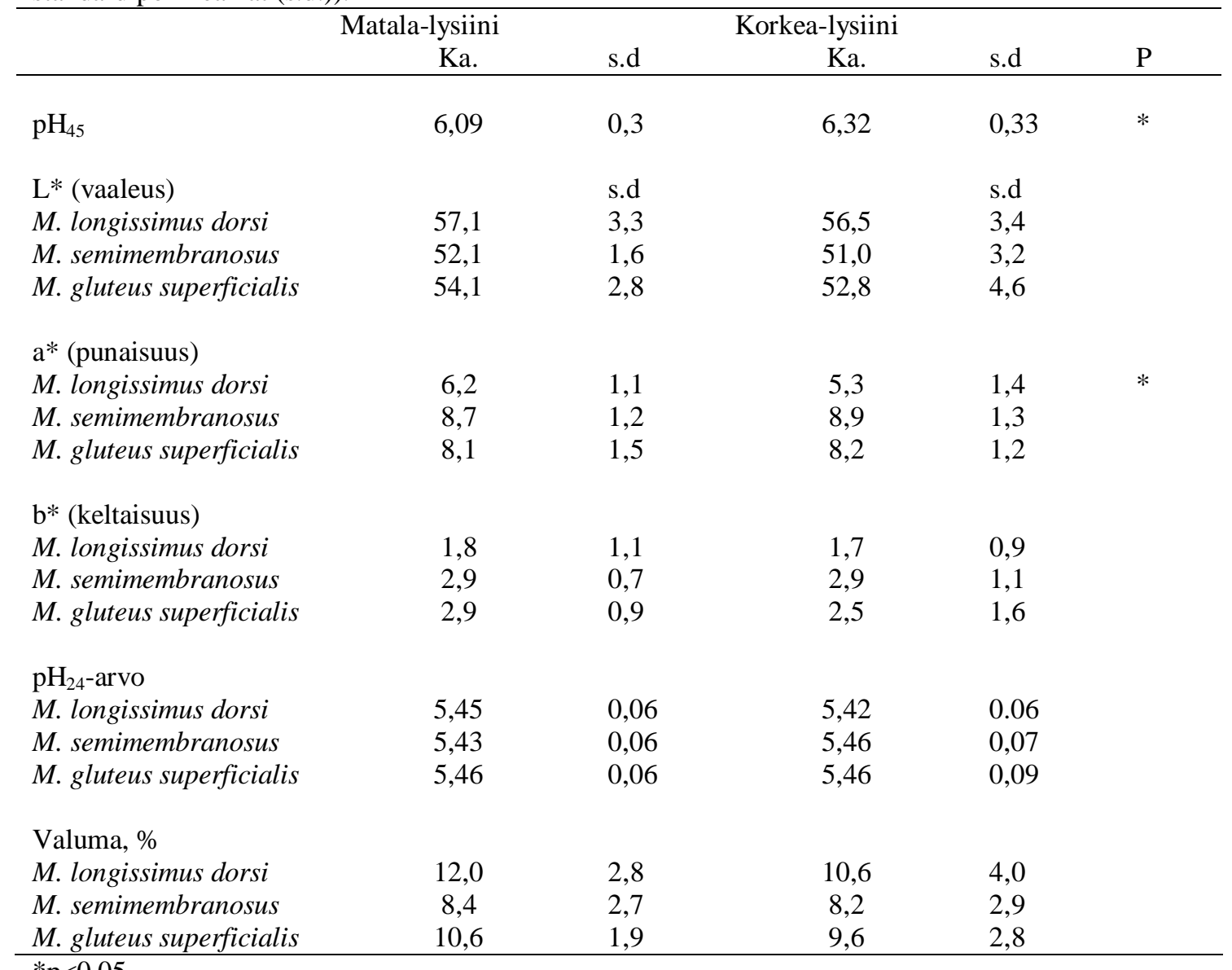
$* \mathrm{p}<0,05$

\section{Johtopäätökset}

Kun siat teurastetaan saman ikäisinä, vähän lysiiniä saaneiden sikojen vaaleissa lihaksissa lihassolut olivat pienempiä, lihasten glykolyyttinen potentiaali oli korkeampi ja pH-arvo laski nopeammin teurastuksen jälkeen kuin enemmän lysiiniä saaneilla. Ilmeisesti syy eroihin tutkituissa ominaisuuksissa oli myös ero proteiinipitoisuudessa. Hyvän lihan laadun kannalta on tärkeää, että siat ruokitaan riittävän hyvin. Lihasten glykogeenipitoisuuteen teurastushetkellä on kiinnitettävä huomiota, ettei se nouse liian suureksi, etenkin jos käytetään glykogeenia säästäviä teurastustapoja. 


\section{Kirjallisuus}

Andersen, P. 1975. Capillary density in skeletal muscle of man. Acta Physiol. Scand. 95: 203-205.

Barton-Gade, P. 1981. The measurement of meat quality in pigs post mortem. Porcine stress and meat qualitycauses and possible solutions to the problems. pp. 205-218. (Ed. T. Froystein, E. Slinde \& N. Standal). Agricultural Food Research Society. Ås, Norway. 359 p.

Brooke, M. H. \& Kaiser, K. K. 1970. Muscle fiber types: How many and what kind. Arch. Neurol. 123: 369379.

Henckel, P., Karlsson, A., Jensen, M.T., Oksbjerg, N. \& Søholm Petersen, J. 2002. Metabolic conditions in Porcine longissimus muscle immediately pre-slaughter and its influence on peri- and post mortem energy metabolism. Meat Sci. 62: 145-155.

Honikel, K.O. \& Kim, C.-J. 1985. Über die Ursachen der Entstehung von PSE-Schweinefleisch. Fleischwirtsch. 65:1125-1131.

Immonen, K. 2000. Bovine muscle glycogen concentration in relation to diet, slaughter and ultimate beef quality. Diss. EKT-series 1203. University of Helsinki. Dept. of Food Technology. $64+44$ p.

Monin, G. \& Sellier, P. 1985. Pork of low technological quality with normal rate of muscle pH fall in the immediate post-mortem period: The case of the Hampshire breed. Meat Sci. 13: 49-63.

Puolanne, E., Ruusunen, M., Partanen, K., Pösö, R., Sepponen, K. \& Kylä-Puhju, M. 2003. Sian fysiologisten ominaisuuksien yhteys lihan laatuun ja eläinten hyvinvointiin. MMM, Makera-hanke 4013/501/99. Loppuraportti 2003.

SAS. 1999. SAS/STAT User's Guide, Version 8, Cary, NC:SAS Institute Inc.

Schäfer, A., Rosenvold, K., Purslow, P.P., Andersen, H.J. \& Henckel, P. 2002. Physiological and structural events post mortem of importance for drip loss in pork. Meat Sci. 61: 355-366. 